\title{
Pulmonary rehabilitation and the BODE index in COPD
}

\author{
C.G. Cote* and B.R. Celli"
}

ABSTRACT: The BODE index, which integrates body mass index, airflow limitation (forced expiratory volume in one second), dyspnoea and 6-min walk distance, predicts mortality in chronic obstructive pulmonary disease (COPD). Pulmonary rehabilitation (PR) improves some components of BODE. It was hypothesised that changes in BODE may reflect the effects of PR.

To test this, participation in PR was offered to 246 patients (BODE quartiles 2-4). The patients were divided as follows: no PR (130 who declined rehabilitation or who dropped out from PR), and PR (116 who completed PR). BODE was determined at entry, after PR, and at 1 and 2 yrs. Other outcomes were: length of stay (LOS) for respiratory-related hospitalisations and mortality.

At entry, the two groups had similar age and comorbidity but different BODE. After PR, the BODE improved by $19 \%$ and returned to baseline after 2 yrs. The BODE worsened in the no PR group by $4 \%$ at 12 months and $18 \%$ at 2 yrs. Respiratory mortality at 2 yrs for PR was 7\%, compared with $39 \%$ for no PR. LOS at 1 yr for COPD decreased $20 \%$ in PR, while it increased $25 \%$ in no PR.

In conclusion, pulmonary rehabilitation participation improves BODE and is associated with better outcomes. The BODE index change after pulmonary rehabilitation provides valuable prognostic information.

KEYWORDS: Bode index, chronic obstructive pulmonary disease, pulmonary rehabilitation, survival

hronic obstructive pulmonary disease (COPD) will be the third most frequent cause of death in the world by the year 2020 [1]. It is characterised by poorly reversible airflow limitation and dyspnoea [2-4]. As the disease progresses, some patients develop systemic manifestations, including exercise limitation [4, 5], peripheral muscle dysfunction [5-7], pulmonary hypertension [8], malnutrition [9, 10] and recurrent exacerbations leading to hospitalisations [11]. Due to the lack of effect of most therapies on the decline of lung function $[2,3,12]$, COPD is perceived as being poorly responsive to treatment. However, several studies have identified the value of correcting gas exchange $[13,14]$, improving walk distance [2, 3, 15-17], degree of functional breathlessness [18] and nutritional status [19]. Therefore, assessing and treating COPD solely on the basis of airflow limitation negates the importance of other treatable clinical manifestations of the disease.

Pulmonary rehabilitation (PR) is a therapy that, without affecting lung function, impacts on some of the other consequences of the disease. PR reduces healthcare resource utilisation (HCRU) $[20,21]$, improves health status [22], decreases dyspnoea $[18,23]$ and enhances exercise capacity
[24-27]. Two of these outcomes, dyspnoea and exercise capacity, are components of the body mass index (BMI) (B), degree of obstruction $(\mathrm{O})$, dyspnoea (D) and exercise capacity (E), or BODE index [28] and are also independent predictors of survival in COPD [29, 30]. Based on these associations, the current authors planned an observational study to test the hypothesis that PR improves the BODE index and that the change in BODE relates to survival over time. The study have been inappropriate to deny participation in pulmonary rehabilitation to patients willing to partake in it over a 3-yr period.

\section{MATERIAL AND METHODS Study design}

This prospective observational cohort study comprised 246 consecutive outpatients $(98 \%$ male), with a diagnosis of COPD at the Bay Pines Veterans Affairs (VA) Medical Center, FL, USA. These patients are part of a larger multicentre BODE cohort study on COPD, the details of which have already been reported [28]. The study was approved by the human review-board of the institution. Patients signed a consent form and were followed for $\geqslant 2$ yrs or until death. was observational in design because it would
AFFILIATIONS

*Division of Pulmonary-Critical Care Medicine, The Bay Pines Foundation, Bay Pines VA Medical Center, University of South Florida, Tampa, $\mathrm{FL}$, and

\#Division of Pulmonary and Critical Care Medicine, Caritas-St Elizabeth's Medical Center, Tufts University School of Medicine, Boston, MA, USA.

\section{CORRESPONDENCE}

B.R. Celli

Caritas-St Elizabeths Medical Center 736 Cambridge St

Boston

MA 02135

USA

Fax: 16175627756

E-mail: bcelli@copdnet.org

Received:

April 152005

Accepted after revision:

July 082005 
COPD was determined by a history of smoking $>10$ pack-yrs, and a post-bronchodilator forced expiratory volume in one second $(\mathrm{FEV} 1) /$ forced vital capacity $<0.7$. The spirometry and lung volumes were determined following the American Thoracic Society (ATS) criteria [31]. The patients were receiving optimal medical therapy following current recommendations [2, 3]. The exclusion criteria were: 1) contraindications to PR as identified in guidelines [32]; 2) illness that could cause death within 3 yrs; 3) asthma as defined by medical history, as well as by $>15 \% \mathrm{FEV} 1$ or $200 \mathrm{~mL}$ increase after $200 \mu \mathrm{g}$ of inhaled albuterol; 4) inability to perform the tests; 5) myocardial infarction within 4 months; 6) unstable angina; or 7) congestive heart failure stage III or IV in the New York Heart Association classification.

Age, sex, race, smoking history in pack-yrs, current smoking status, history of oxygen dependence, medications and corticosteroids use and dosing, room air arterial blood gas at rest, and oxygen saturation with exercise, were all recorded. The validated Charlson index was used to determine the degree of comorbidity [33]. The BODE index was calculated as described [28] at baseline, after PR and every 6 months for $\geqslant 2$ yrs or until death.

Patients were grouped according to their participation as follows: the no PR group included those patients who voluntarily declined participation or who dropped out from the PR programme before graduation. The PR group included those patients who agreed to participate, and who completed all sessions and graduated. Patients were considered PR responders if there was a change in BODE index of -1 point or more. A summary of the study is shown in figure 1 . PR consisted of 24, 2-h sessions over 8 weeks, including education, psychosocial support and supervised exercise training. Exercise intensity was individualised. Patients used a treadmill, arm cycling, and arm and leg weights. Participation in a maintenance exercise programme was offered to all graduates. Patients were encouraged to remain physically active. Active smokers were allowed to participate in PR only after

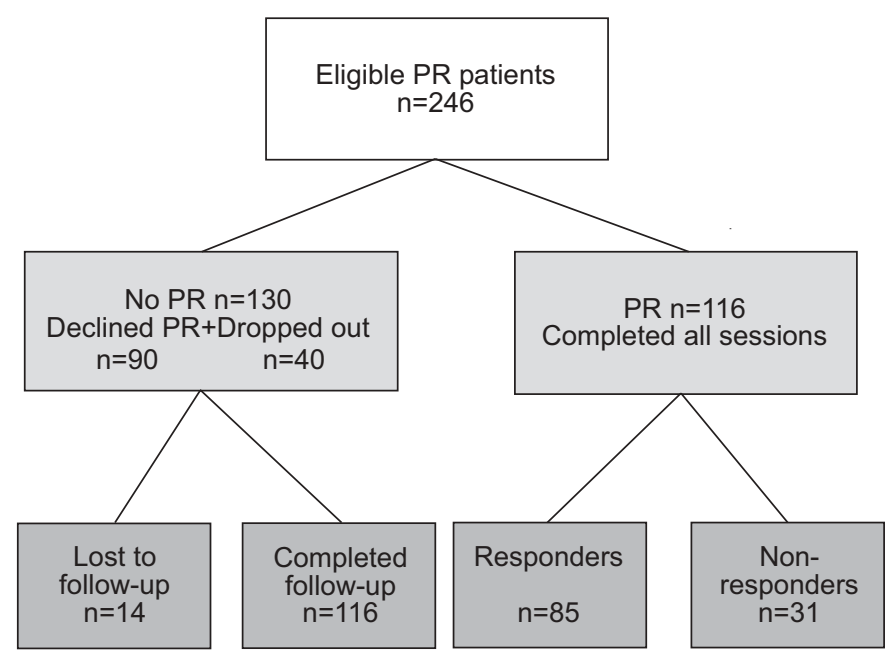

FIGURE 1. Description of the observational study of pulmonary rehabilitation (PR) offered to patients with chronic obstructive pulmonary disease. graduation from a smoking cessation programme and all patients were offered a referral to the programme.

\section{Study outcomes}

Mortality was confirmed by reviewing the computerised Bay Pines VA Medical Centre medical record system (CPRS), and verified by contacting the patient's next of kin whenever available. Hospital length of stay (LOS) for admissions due to COPD exacerbations was reviewed for 12 months prior to enrolment for all patients, and prospectively captured for $1 \mathrm{yr}$ following enrolment into the protocol. Only Bay Pines VA Medical Centre hospitalisations were included in the analysis.

\section{Statistical analyses}

Data for continuous variables are presented as mean \pm SD. Inter- and intra-group comparisons were completed using both paired and unpaired t-tests for continuous variables and Chisquared for categorical variables. The factors associated with mortality were analysed using Cox proportional hazards analyses [34]. Kaplan-Meier analysis was used to describe the survival distribution of the groups. A p-value $<0.05$ was deemed significant. All analyses were completed using an intent-to-treat design.

\section{RESULTS}

The population consisted primarily of white males (98\%). The mean FEV1 was $0.99 \mathrm{~L}$ (32\% of predicted). The mean follow-up was 39 months, ranging $3-87$ months. A total of $57 \%$ of the patients were oxygen dependent and 15\% were receiving systemic corticosteroids. Their entry mean BODE index was $6.07 \pm 2.01$, consistent with quartile $3[28]$, and $27 \%$ of the patients were current smokers. There were 80 deaths in 2 yrs $(33 \%)$, the majority of which were of respiratory origin $(83 \%)$.

The characteristics of the groups are shown in table 1. A total of $53 \%$ of patients declined participation in PR or dropped out of the programme voluntarily. These patients had similar age and FEV1 than the PR patients. However, they had a higher BODE $(\mathrm{p}<0.0001)$, a lower BMI $(\mathrm{p}<0.002)$ and 6-min walk distance (6MWD; $<<0.0001)$, a worse FEV1 $(p<0.001)$, and had more dyspnoea $(p<0.0001)$. They had a similar history of packs per year, but a higher percentage of them were current smokers (30 versus $23 \%$; $\mathrm{p}<0.001$ ). All patients participating in PR who were smokers agreed to join a smoking cessation programme prior to PR. Only $8 \%$ of current smokers in the no PR group participated in the smoking cessation programme. Altogether, $27 \%$ of no PR and $5 \%$ of PR participants were currently smoking at the end of the follow-up period $(p<0.0026)$. More patients who refused participation in PR were receiving oral corticosteroids and were on chronic oxygen therapy $(\mathrm{p}<0.001)$.

Even though the programme was offered free of direct cost, only $63 \%$ of all qualifying patients agreed to participate in PR and only $47 \%$ of patients graduated from the programme $(25 \%$ drop-out rate). The drop-out patients were considered together with the no PR group because they had similar clinical characteristics. These included: age, sex distribution, FEV1, use of oxygen and corticosteroids, baseline oxygenation and carbon dioxide, as well as BODE score. The only differences was a lesser degree of comorbidity in the drop out versus no PR (Charlson of $4.3+1.7$ compared with $5.3+1.7 ; \mathrm{p}=0.007$ ) and a 


\begin{tabular}{|c|c|c|c|}
\hline \multirow[t]{2}{*}{$\begin{array}{l}\text { Baseline clinio } \\
\text { according to } t \\
\text { rehabilitation }\end{array}$} & \multirow[t]{2}{*}{$\begin{array}{l}\text { al characte } \\
\text { eir particip }\end{array}$} & \multirow[b]{2}{*}{ All PR } & \multirow[b]{2}{*}{$p$-value } \\
\hline & & & \\
\hline Patients n & 130 & 116 & \\
\hline Age yrs & $69.5 \pm 8.7$ & $69.5 \pm 7.7$ & 0.79 \\
\hline FEV1 L & $0.93 \pm 0.29$ & $1.05 \pm 0.3$ & 0.21 \\
\hline FEV $_{1} \%$ Pred & $29.9 \pm 9.1$ & $33.3 \pm 8.6$ & 0.03 \\
\hline MMRC dyspnoea scale & $3.15 \pm 0.76$ & $2.65 \pm 0.63$ & $<0.0001$ \\
\hline 6MWD m & $229.3 \pm 113$ & $343.1 \pm 100$ & $<0.0001$ \\
\hline$B M I \mathbf{k g} \cdot \mathbf{m}^{-2}$ & $24.5 \pm 5.8$ & $26.8 \pm 5.5$ & 0.005 \\
\hline BODE index & $6.94 \pm 1.97$ & $5.07 \pm 1.5$ & $<0.0001$ \\
\hline Charlson index & $5 \pm 2.13$ & $4.53 \pm 1.93$ & 0.06 \\
\hline Chronic $\mathrm{O}_{2}$ use $\%$ & 61.8 & 50 & $<0.001$ \\
\hline Chronic steroid use \% & 16.7 & 7.7 & $<0.01$ \\
\hline $\mathrm{Pa}, \mathrm{O}_{2} \mathrm{mmHg}$ & $68.4 \pm 11$ & $71 \pm 11$ & 0.10 \\
\hline $\mathrm{Pa}_{\mathrm{a}} \mathrm{CO}_{2} \mathrm{mmHg}$ & $42.7 \pm 7.8$ & $40.9 \pm 6.6$ & 0.12 \\
\hline $\mathrm{O}_{2}$ saturation with exercise & $87.2 \pm 6$ & $89.7 \pm 4.8$ & 0.02 \\
\hline Chronic bronchitis \% & 53 & 59 & 0.12 \\
\hline Current tobacco use at entry \% & 29.7 & 27 & 0.001 \\
\hline Smoking Hx Packs $\cdot \mathrm{yr}^{-1}$ & $93.7 \pm 53$ & $91.3 \pm 43$ & 0.24 \\
\hline \multicolumn{4}{|c|}{$\begin{array}{l}\text { Data presented as mean } \pm \mathrm{SD} \text {, unless otherwise stated. } \mathrm{FEV} 1 \text { : forced expiratory } \\
\text { volume in one second; \% pred: percentage of predicted; MMRC: Modified } \\
\text { Medical Research Council; } 6 \mathrm{MWD} \text { : } 6 \text {-minute walk distance; } \mathrm{BMI} \text { : body mass } \\
\text { index; } \mathrm{Pa}_{\mathrm{a}} \mathrm{O}_{2} \text { : arterial oxygen tension; } \mathrm{Pa}_{\mathrm{a}} \mathrm{CO}_{2} \text { : carbon dioxide arterial tension; } \mathrm{Hx} \text { : } \\
\text { history. }\end{array}$} \\
\hline
\end{tabular}

higher percentage of current smokers in that group (38\% compared with $26 \% ; \mathrm{p}=0.001)$. To assess the factors influencing compliance with participation in PR (drop-out risk) the current authors developed a multiple regression analysis model using graduation from $\mathrm{PR}$ as the dependent variable. Only a worse entry BODE, current smoking, and a history of attendance to a smoking cessation programme contributed to the model $\left(\mathrm{r}^{2}=26 ; \mathrm{p}<0.0001\right)$. Whereas $49 \%$ of $\mathrm{PR}$ graduates $(\mathrm{p}<0.0001)$ reported participation in some type of exercise after graduation (daily walks, joined a gym or exercised in the Young Men Christian Association), only 10\% of the patients in the no PR group reported participation in regular exercise.

The change in BODE for patients participating in PR is shown in figure 2. The mean change for the PR group was -0.9 $(\mathrm{p}<0.0001)$ at 3 months. Altogether, 83 patients, or $71 \%$, had $>1$ unit improvement in BODE. Of these, 29 patients $(25 \%)$ improved the BODE index by -2 points, 54 patients ( $47 \%$ ) by -1 point. No change in BODE was seen in 25 patients $(22 \%)$ and eight patients $(7 \%)$ showed worsening of the index. As shown in table 2, after the initial improvement of $19 \%$, PR participants showed a return of the BODE index to baseline at $1 \mathrm{yr}(4 \%)$ and remained stable after 2 yrs. The patients who did not partake in PR showed a decline in BODE at $1 \mathrm{yr}$ of $4 \%$, and a worsening in BODE at 2 yrs of $18 \%$. The changes in the individual components of BODE after 2 yrs of follow-up were as follows: no PR patients showed a $160 \mathrm{~mL}$ decline in FEV1, higher than PR participants who showed a $20 \mathrm{~mL}$ decline $(p<0.0001)$. All groups showed a decline in exercise capacity

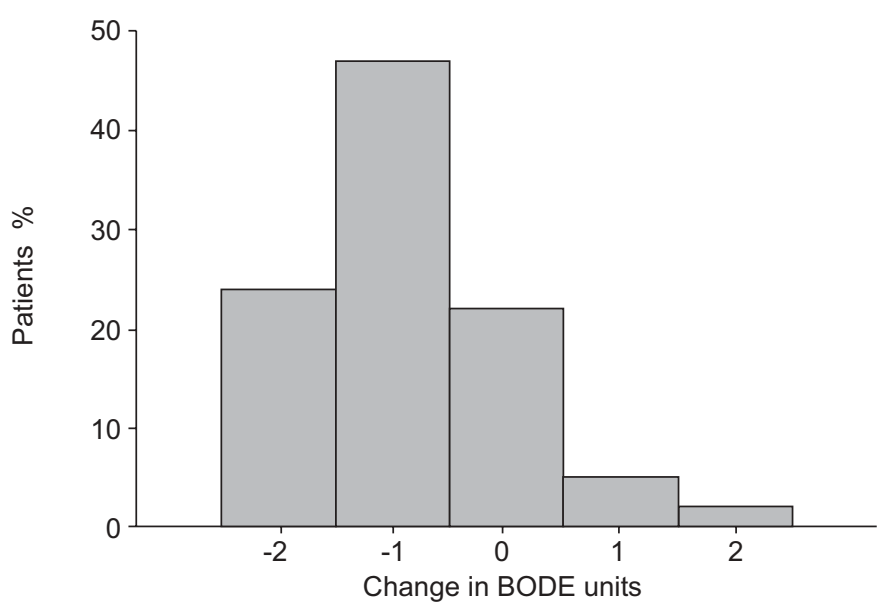

FIGURE 2. Distribution of the change in BODE index in all patients completing pulmonary rehabilitation ( 3 months). Improvement in the BODE is manifested by decreases in the index, whereas an increase in the value implies worsening in the prognosis. Over $70 \%$ of the patients had an improvement of at least one unit in the BODE index.

\begin{tabular}{|c|c|c|c|c|c|}
\hline TABLE 2 & \multicolumn{5}{|c|}{$\begin{array}{l}\text { Change in BODE following pulmonary } \\
\text { rehabilitation (PR) in the patients enrolled in PR } \\
\text { as well as the change in patients who did not } \\
\text { enrol in rehabilitation (no PR) }\end{array}$} \\
\hline Groups & $\begin{array}{c}\text { Subjects } \\
n\end{array}$ & Baseline & $\begin{array}{c}\text { Post-PR } \\
\text { (3 months) }\end{array}$ & $1 \mathrm{yr}$ & 2 yrs \\
\hline No PR & 130 & $6.94 \pm 1.97$ & $6.81 \pm 1.92$ & $6.58 \pm 2.1$ & $7.22 \pm 2^{\bullet}$ \\
\hline $\mathbf{P R}^{\#}$ & 116 & $5.07 \pm 1.5$ & $4.18 \pm 1.68$ & $5.0 \pm 2.1$ & $5.11 \pm 2.3^{\circ}$ \\
\hline $\begin{array}{l}\#: p<0 . \\
\text { compare }\end{array}$ & $\begin{array}{l}\text { between } \\
\text { with basel }\end{array}$ & PR and $P F$ & all time poir & $\because: p<0.00$ & by ANOVA \\
\hline
\end{tabular}

(no PR $-53 \mathrm{~m}$ versus PR $-14 \mathrm{~m}$; $\mathrm{p}<0.001$ ). PR responders had a decrease of -0.14 MRC dyspnoea units, whereas no PR showed an increase in the MRC score of 0.38 units, respectively $(p<0.001)$. There were no changes in BMI in either group.

The hospitalisation rate is shown in table 3. The highest rate of hospitalisation and the longest LOS for COPD admissions in the year preceding enrolment were seen in the no PR group. This pattern persisted in the year post-enrolment with an overall increase in LOS. Hospital utilisation was significantly lower among patients participating in PR, with the most benefit seen among those who decreased their BODE index $\geqslant 1$ point. LOS declined $20 \%$ for the all PR participants and by $65 \%$ for those PR patients improving the BODE index by 2 points. LOS increased 25\% for no PR patients.

There were 80 deaths in 2 yrs. The no PR group (130 patients) had 66 deaths; 57 were respiratory-related, four were cardiovascular, three were related to other malignancies, and the rest to various causes. In the PR group there were 13 deaths; eight patients died from respiratory illness, three from acute 


\begin{tabular}{|c|c|c|c|c|}
\hline \multirow[t]{2}{*}{ TABLE 3} & \multicolumn{4}{|c|}{$\begin{array}{l}\text { Hospitalisation rate and length of hospital stay } \\
1 \mathrm{yr} \text { prior to and } 1 \mathrm{yr} \text { after enrolment in all } \\
\text { patients participating in the study }\end{array}$} \\
\hline & & & All no PR & PR \\
\hline \multirow{2}{*}{\multicolumn{2}{|c|}{ Total/COPD yr }} & Pre & $0.56 \pm 1.07$ & $0.49 \pm 0.91$ \\
\hline & & Post & $0.42 \pm 1.21$ & $0.26 \pm 00.79^{\# \cdot} \cdot$ \\
\hline \multirow{2}{*}{\multicolumn{2}{|c|}{ Total COPD LOS days }} & Pre & $3.71 \pm 6.7$ & $1.81 \pm 4.8^{\#}$ \\
\hline & & Post & $4.62 \pm 9.9$ & $1.45 \pm 6.23^{\# \cdot \bullet}$ \\
\hline \multicolumn{5}{|c|}{$\begin{array}{l}\text { Data presented as mean } \pm \mathrm{SD} \text {. PR: pulmonary rehabilitation; COPD: admissions } \\
\text { due to chronic obstructive pulmonary disease exacerbations; LOS: length of } \\
\text { hospital stay. }{ }^{\#:}: p<0.005 \text { PR compared with no PR by t-test for independent } \\
\text { variables; }{ }^{~: ~} p<0.001 \text { post-rehabilitation compared with pre-rehabilitation by } \\
\text { t-test for paired observations. }\end{array}$} \\
\hline
\end{tabular}

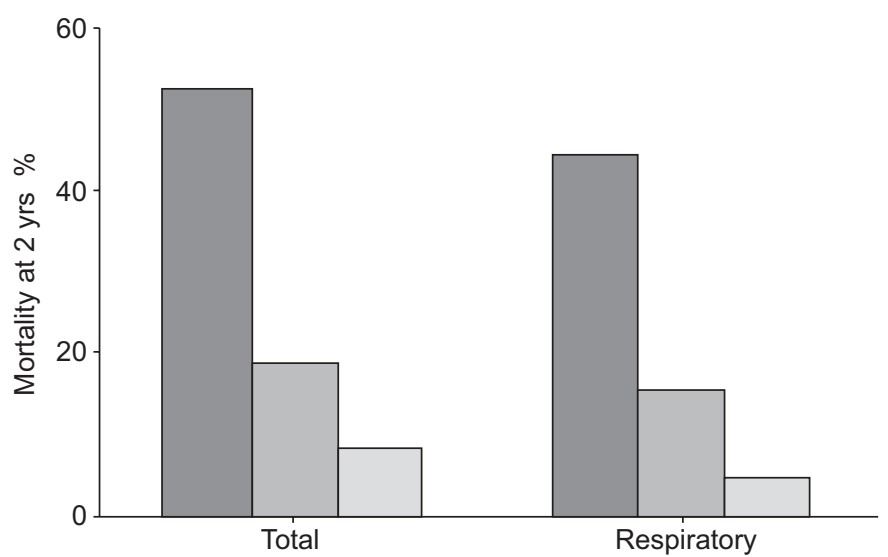

FIGURE 3. All-cause and respiratory mortality at $2 \mathrm{yrs}$ in patients with no pulmonary rehabilitation (PR; $\square$ ), PR nonresponder patients ( $\square$ ) and PR responder patients $(\square)$

myocardial infarction, and two from cancer. Figure 3 shows that mortality was significantly higher in patients who did not enrol in rehabilitation and lowest for patients who had $>1$ unit change in BODE after PR. The difference in mortality between responders and nonresponders did not reach statistical significance, most likely because of the low number of deaths in either group (eight and five, respectively). Figure 4 shows

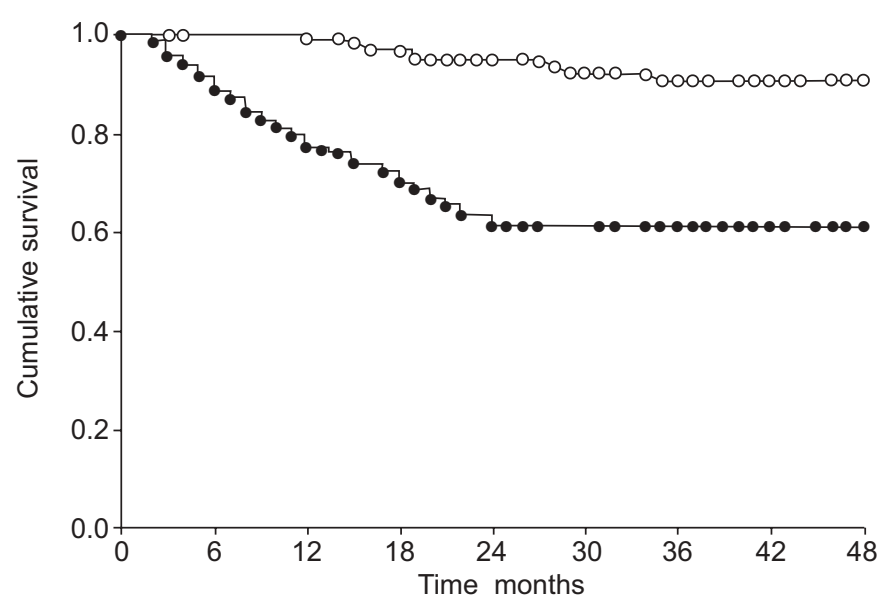

FIGURE 4. Kaplan-Meier survival curves for all patients. Patients participating in pulmonary rehabilitation $(\bigcirc)$ manifested a survival advantage compared with patients who declined participation in pulmonary rehabilitation $(\mathbf{\bullet})$. $\mathrm{p}<0.0001$ by log rank.

\begin{tabular}{llc} 
TABLE 5 & $\begin{array}{l}\text { Cox proportional hazard analysis for all patients } \\
\text { enroled in the study with death as the dependent } \\
\text { variable }\end{array}$ \\
& \multicolumn{1}{c}{ Hazard ratio } & p-value \\
\hline BODE index & $1.817(1.715-2.14)$ & $<0.0001$ \\
Participation in PR & $0.569(0.324-0.999)$ & 0.023 \\
Charlson index & $1.195(1.018-1.492)$ & 0.036 \\
Age & $0.953(0.913-0.996)$ & 0.05 \\
\hline
\end{tabular}

Data presented as n (95\% confidence interval), unless otherwise stated. PR pulmonary rehabilitation.

the Kaplan-Meier survival curves for the two groups. By log rank analysis there was a difference between PR and no PR $(\mathrm{p}<0.001)$. Patients participating in PR had a lower mortality than patients that did not enrol in rehabilitation across the different BODE quartiles (table 4). A Cox proportional hazard analysis (table 5) showed that the post-rehabilitation BODE, participation in rehabilitation and degree of comorbidity were the only factors participating in the prediction of mortality.

TABLE 4 Mortality at $2 \mathrm{yrs}$ in patients who participated in pulmonary rehabilitation (PR) compared with nonparticipants, independent of the severity of disease as measured by the BODE index

\begin{tabular}{|c|c|c|c|c|c|c|c|}
\hline \multirow[t]{2}{*}{ BODE quartile } & \multicolumn{3}{|c|}{ No $\mathrm{PR}^{\#}$} & \multicolumn{3}{|c|}{$P^{*}$} & \multirow{2}{*}{$\begin{array}{l}\text { p-value for difference in } \\
\text { mortality }\end{array}$} \\
\hline & BODE & Mortality & Patients n & BODE & Mortality & Patients n & \\
\hline Q2 & 3.88 & $24 \%$ & 17 & 3.64 & $0 \%$ & 45 & $<0.0001$ \\
\hline Q3 & 5.53 & $30 \%$ & 40 & 5.38 & $15 \%$ & 52 & $<0.0001$ \\
\hline Q4 & 8.4 & $71 \%$ & 74 & 7.26 & $26 \%$ & 19 & $<0.0001$ \\
\hline
\end{tabular}

\#: $n=130$; overall mortality $52 \% ;{ }^{\circ}: \mathrm{n}=116$; overall mortality $12 \%$. 


\section{DISCUSSION}

This observational study of patients with COPD offered participation in PR has several important findings. First, the response to PR can be objectively measured using the BODE index. Secondly, the change in BODE index provides information regarding ultimate survival. Thirdly, participation in a rehabilitation programme is associated with a decrease in hospitalisations.

Although PR has minimal effect on lung function, it improves dyspnoea [18, 23], exercise capacity [24-26], health status [22] and healthcare resource utilisation [20, 21]. Two of these outcomes, dyspnoea and exercise capacity, are components of the BODE index. As such, the BODE index could be used to evaluate the effect of PR. The current authors defined one unit change in BODE as being clinically significant because it implies a change in any of its component of a magnitude large enough to influence clinical outcomes. Indeed, one unit change in the Modified Medical Research Council scale predicts mortality [29]. Likewise, one unit change in the 6MWD in the BODE score far exceeds the $50 \mathrm{~m}$ considered to be clinically significant changes for this test [35]. Similarly, one unit change in the FEV1 component of the BODE index reflects the thresholds that have been accepted by the ATS/European Respiratory Society and Global Initiative for Chronic Obstructive Lung Disease (GOLD) as the basis for the physiological staging of COPD $[2,3]$. Using this conservative threshold, $71 \%$ of the patients participating in PR improved the BODE index, a finding that supports that BODE is a valid tool to evaluate the integrated response to interventions.

Although showing that BODE can reflect the response to therapy is important, it is more important to determine the true meaning of this change. In the current study, the authors show that disease modification as measured by the BODE index is possible after PR, and that the observed change confers a predictive information heretofore unavailable. The current authors have previously shown that patients with BODE index in the third and fourth quartiles have a very high mortality at 52 months [28]. Accordingly, the predicted 2-yr mortality for patients with a BODE index in quartiles 3 and 4, was 20 and $30 \%$, respectively [28]. In the current study, the entire patient population (PR and No PR) had an entry BODE index of 6.06, consistent with quartile 3 of BODE. Their observed 2-yr mortality rate was $33 \%$, which approximated the predicted mortality for that quartile. PR participants as a group had an initial BODE index of 5.07, which decreased significantly to 4.18 after PR. Compared with the current authors original report, they shifted from quartile 3 to 2 and their initially predicted mortality of 20 to $30 \%$ changed to an observed mortality of $11.2 \%$. No PR patients exhibited an entry BODE index approaching quartile 4 (6.94), and showed a close to $20 \%$ worsening of BODE overtime. Their observed mortality rate was the highest $(50 \%)$. The difference in mortality between the two groups is likely due to self-selection, as patients not participating in rehabilitation were sicker and continued to smoke more than the patients in the PR group. Interestingly, the Charlson score of the no PR and PR groups was similar, indicating that comorbidity may not have played a significant role in their overall outcomes. Taken together, these data demonstrate that the BODE index can not only be used to reflect the global changes induced by $\mathrm{PR}$, but also that a change in BODE index may actually imply a change in outcome, so in a sense $B O D E$ can be considered a surrogate marker for mortality.

It is likely that the higher severity of disease as measured by BODE explains the observed mortality in the no PR group. Indeed, that group had a higher percentage of patients with BODE index in the 4th quartile when compared with the PR participants, and a higher percentage of current smokers. The current authors have shown that for every point increase in the BODE index there is a corresponding increase in mortality [28]. In addition, the higher number of patients on chronic corticosteroids and supplemental oxygen in the no PR group support this possibility. However, as shown in table 5, those patients in the PR group with BODE quartile 4 showed the highest survival advantage when compared with their counterparts in the no PR group. Using multivariate analysis with death as the dependent variable, the only variables entering the predictive model were the BODE index, participation in PR and degree of comorbidity. Finally, because the small number of patients who continued to smoke in the PR group may not have allowed this variable to enter in the predictive model, it is possible that the difference in the persistent higher smoking prevalence in patients who did not partake in rehabilitation compared with that of patients who did participate in PR played a role in the increased mortality in the former group.

To the current authors' knowledge, this study is the first that attempts to identify the factors that lead patients to decline or to drop-out from participation in PR. A high BODE index, indicating more severe multidimensional affliction by COPD, current smoking and prior attendance to a smoking cessation programme were the only factors that identified such patients. This demonstrates the great need to better characterise and study this population, as their natural course is very poor. Indeed, the mortality in that group (which continued to receive regular optimal care at a COPD clinic) was higher than the expected mortality in the original BODE cohort. It is extremely urgent that alternative therapeutic strategies aimed at these individuals are developed. Furthermore, the capacity to treat smoking addiction as a primary disease must be developed, because this certainly was an important reason for the continued deterioration of these patients. The problem is very large, indeed, it is disturbing that in a recent work by BOURBEAU et al. [20], close to $60 \%$ of the patients declined participation in a programme of pro-active management of COPD. In that study, there was no mention of any factor leading to lack of participation in the therapeutic trial. The remarkably similar number of decliners of participation in the current study and that of BORBEAU et al. [20] suggests the presence of other, yet undefined, elements related to the active participation of patients in their own care.

This study also documented improvement in utilisation of healthcare resources among PR participants. This confirms the results of previous studies $[20,21]$ that showed a significant improvement in hospitalisation rate and hospital stay after pulmonary rehabilitation. Prior studies assessing the long-term effects of PR have reported that gains in health-related quality of life and HCRU, persist for up to 2 yrs following PR, and that other outcomes, such as improvements in dyspnoea and functional capacity, are lost if patients fail to remain active 
$[26,27,36]$. In the current study, $29 \%$ of PR graduates joined a supervised maintenance exercise programme and continued to exercise (three times per week) throughout their observational period, and as many as $49 \%$ of graduates reported that they continued to exercise on a regular basis for at least $1 \mathrm{yr}$ following PR. Perhaps this factor contributed to their improved outcomes.

This study had some limitations. First, it was not a randomised trial. However, the current authors felt that the evidence of the beneficial effects of pulmonary rehabilitation were such that a randomised trial that condemned the patients willing to participate in rehabilitation to a passive control group with 2-yr survival as an outcome was not ethically justified. Further, several reviews have suggested that well planned observational studies provide information that closely resemble that provided by randomised trials [37, 38]. Secondly, few females were included. Therefore, the findings from the current study may not be applicable to both sexes and similar studies with a large group of females may be needed before the conclusions can be extended to both sexes. Thirdly, the study population is restricted to patients attending a pulmonary clinic with BODE quartiles $2-4$, thus, the findings from the current study could only be applicable to that group of patients. However, because PR is recommended for patients with symptomatic lung disease, most patients attending rehabilitation will have BODE index similar to the ones in the current study.

In summary, the current study has shown that the BODE index captures the beneficial effects induced by pulmonary rehabilitation. More importantly, the post-rehabilitation response in BODE may play a role in their long-term survival. Those patients who declined participation in pulmonary rehabilitation or who dropped out from the programme had higher BODE index values and a worse progression of disease. These patients have a poor prognosis and research must be devoted to characterise the reasons and possible interventions to alter their outcome. Finally, the current authors confirm that pulmonary rehabilitation is also associated with decreased utilisation of healthcare resources, making this therapy cost effective and essential in the management of symptomatic patients with chronic obstructive pulmonary disease.

\section{REFERENCES}

1 Murray CJL, Lopez AD. Mortality by cause for eight regions of the world: Global Burden of Disease Study. Lancet 1997; 349: 1269-1276.

2 Celli BR, MacNee W. Standards for the diagnosis and treatment of COPD. Eur Respir J 2004; 23: 932-946.

3 Pauwels R, Sonia Buist A, Calverley P, Jenkins C, Hurd S. Global strategy for the diagnosis, management and prevention of chronic obstructive pulmonary disease. NHLBI/WHO Global Initiative for Chronic Obstructive Lung Disease (GOLD). Workshop summary. Am J Respir Crit Care Med 2001; 163: 1256-1276.

4 Hay JG, Stone P, Carter J, et al. Bronchodilator reversibility, exercise performance and breathlessness in stable chronic obstructive pulmonary disease. Eur Respir J 1992; 5: 659-664.
5 Gosselink R, Troosters T, Decramer M. Peripheral muscle weakness contributes to exercise limitation in COPD. Am J Respir Crit Care Med 1996; 153: 976-980.

6 Mador MJ, Deniz O, Aggarwal A, Kufel TJ. Quadriceps fatigability after single muscle exercise in patients with chronic obstructive pulmonary disease. Am J Respir Crit Care Med 2003; 168: 102-108.

7 Bernard S, LeBlanc P, Whittom F, et al. Peripheral muscle weakness in patients with chronic obstructive pulmonary disease. Am J Respir Crit Care Med 1998; 158: 629-634

8 France AJ, Prescott RJ, Biernacki W, Muir AL, MacNee W. Does right ventricular function predict survival in patients with chronic obstructive lung disease? Thorax 1988; 43: 621-626.

9 Wouters EFM, Schols AMWJ. Prevalence and pathophysiology of nutritional depletion in chronic obstructive pulmonary disease. Respir Med 1993; 87: Suppl. B, 45-47.

10 Schols AM, Soeters P, Dingemans M, Mostert R, Frantzen P, Wouters E. Prevalence and characteristics of nutritional depletion in patients with stable COPD eligible for pulmonary rehabilitation. Am Rev Respir Dis 147: 1151-1156.

11 Connors AF Jr, Dawson NV, Thomas C, et al. Outcomes following acute exacerbation of severe chronic obstructive pulmonary disease: the SUPPORT Investigators (Study to Understand Prognosis and Preferences for Outcomes and Risks of Treatments). Am J Respir Crit Care Med 1996; 154: 959-967.

12 Anthonisen NR, Wright EC, Hodgkin JE, the IPPB Trial Group. Prognosis in chronic obstructive pulmonary disease. Am Rev Respir Dis 1986; 133: 14-20.

13 Nocturnal Oxygen Therapy Trial Group. Continuous or nocturnal oxygen therapy in hypoxemic chronic obstructive pulmonary disease: a clinical trial. Ann Intern Med 1980; 93: 391-398.

14 Intermittent Positive Pressure Breathing Trial Group. Intermittent positive pressure breathing therapy of chronic obstructive pulmonary disease. Ann Intern Med 1983; 99: 612-620.

15 Vale F, Reardon JZ, ZuWallack RL. The long-term benefits of outpatient pulmonary rehabilitation on exercise endurance and quality of life. Chest 1993; 103: 42-45.

16 O'Donnell DE, McGuire M, Samis L, Webb KA. General exercise training improves ventilatory and peripheral muscle strength and endurance in chronic airflow limitation. Am J Respir Crit Care Med 1998; 157: 1489-1497.

17 Siafakas NM, Vermeire $\mathrm{P}$, Pride NB, et al. Optimal assessment and management of chronic obstructive pulmonary disease (COPD). Eur Respir J 1995; 8: 1398-1420.

18 Reardon J, Awad E, Normandin E, Vale F, Clark B, ZuWallack RL. The effect of comprehensive outpatient pulmonary rehabilitation on dyspnea. Chest 1994; 105: 1046-1052.

19 Schols AM, Slangen J, Volovics L, Wouters EF. Weight loss is a reversible factor in the prognosis of chronic obstructive pulmonary disease. Am J Respir Crit Care Med 1998; 157: 1791-1797.

20 Bourbeau J, Julien M, Maltais F, et al. Reduction in hospital utilization in patients with chronic obstructive pulmonary disease. Arch Intern Med 2003; 163: 585-591. 
21 Griffiths TL, Phillips CJ, Davies S, Burr ML, Campbell IA. Cost effectiveness of an outpatient multidisciplinary pulmonary rehabilitation programme. Thorax 2001; 56: 779-784.

22 Bowen JB, Votto JJ, Thrall RS, et al. Functional status following pulmonary rehabilitation. Chest 2000; 118: 697-703.

23 Lacasse Y, Brosseau L, Milne S, et al. Pulmonary rehabilitation for chronic obstructive pulmonary disease (Cochrane Review). In: The Cochrane Library, Issue 4. Chichester, UK, John Wiley \& Sons, Ltd, 2003.

24 Troosters T, Gosselink R, Decramer M. Short- and longterm effects of outpatient rehabilitation in patients with chronic obstructive pulmonary disease: a randomized trial. Am J Med 2000; 109: 207-212.

25 National Emphysema Treatment Trial Research Group. A Randomized trial comparing lung-volume-reduction surgery with medical therapy for severe emphysema. N Engl J Med 348: 2059-2073.

26 Ries AL, Kaplan RM, Limberg TM, Prewitt LM. The effects of pulmonary rehabilitation on physiologic and psychosocial outcomes in patients with chronic obstructive pulmonary disease. Ann Intern Med 1995; 122: 823-832.

27 Guell R, Casan RP, Belda J, Sangenis M, et al. Long-term effects of outpatient rehabilitation of COPD: A randomized trial. Chest 2000; 117: 976-983.

28 Celli BR, Cote CG, Marin JM, et al. The Body Mass Index, Airflow Obstruction, Dyspnea, Exercise Performance (BODE) index in chronic obstructive pulmonary disease. N Eng J Med 2004; 350: 1005-1012.
29 Nishimura K, Izumi T, Tsukino M, Oga T. Dyspnea is a better predictor of 5-year survival than airway obstruction in patients with COPD. Chest 2002; 121: 1434-1440.

30 Pinto-Plata VM, Cote C, Cabral H, Taylor J, Celli BR. The 6minute walk distance: change over time and value as a predictor of survival in severe COPD. Eur Respir J 2004; 23: 28-33.

31 American Thoracic Society Statement. Lung function testing; selection of reference values and interpretative strategies. Am Rev Resp Dis 1991; 144: 1202-1218.

32 Ries AL, the ACCP/AACVPR Pulmonary Rehabilitation Guidelines Panel. Pulmonary Rehabilitation: Joint ACCP/ AACVPR evidence-based guidelines. J Cardiopulm Rehabil 1997; 17: 371-405.

33 Charlson M, Szatrowski T, Peterson J, Gold J. Validation of a combined comorbidity index. J Clin Epidemiol 1994; 47: $1245-1251$.

34 Cox D. Regression models and life tables (with discussion). J Royal Statistical Soc 1972; A74: 187-220.

35 Redelmeier DA, Bayoumi AM, Goldstein RS, Guyatt GH. Interpreting small differences in functional status: the six minute walk test in chronic lung disease patients. Am J Respir Crit Care Med 1997; 155: 1278-1282.

36 Foglio K, Bianchi L, Bruletti G, et al. Long-term effectiveness of pulmonary rehabilitation in patients with chronic airway obstruction. Eur Respir J 1999; 13: 125-132.

37 Concato J, Shah N, Horwitz RI. Randomized, controlled trials, observational studies, and the hierarchy of research designs. N Engl J Med 2000; 342: 1887-1892.

38 Benson K, Hartz AJ. A comparison of observational studies and randomized, controlled trials. N Engl J Med 2000; 342: 1878-1886. 